\title{
MEDIASI KONFLIK KERATON SURAKARTA MELALUI PENERAPAN LOCAL WISDOM
}

\author{
Mulyanto \\ Dosen Fakultas Hukum Universitas Sebelas Maret Surakarta Solo, Jl. Ir. Sutami 36A Kentingan \\ Surakarta, Telp: (0271) 632916, Fax: (0271) 632916, Hp: 081329046451, Email: \\ sheemoel@yahoo.com
}

\section{Sutapa Mulja Widada}

Dosen Fakultas Hukum Universitas Sebelas Maret Surakarta Solo, Jl. Ir. Sutami 36A Kentingan Surakarta, Telp: (0271) 632916, Fax: (0271) 632916, Hp: 081328328336 , Email: sutapamuljawidada@yahoo.com

\begin{abstract}
ABSTRAK
Tujuan dari penelitian ini untuk mendeskripsikan akar masalah konflik Raja Kembar Keraton dan pola penyelesaian konflik Keraton Surakarta Hadiningrat. Metode penelitian yang digunakan adalah metode sosiolegal yang bersifat deskriptif. Penelitian ini berlokasi di Keraton Surakarta dengan menggunakan data primer maupun data sekunder. Teknik analisis data kualitatif dengan menggunakan interpretasi teoritis. Hasil penelitian menunjukkan bahwa pada dasarnya akar masalah konflik Keraton Surakarta ini berawal sejak meninggalnya Paku Buwana XII pada 11 Juni 2004. Konflik tersebut tentang pewaris tahta kerajaan antara Kanjeng Gusti Pangeran Harya (KGPH) Hangabehi dan KGPH Tedjowulan yang lahir dari ibu yang berbeda. Pola penyelesaian konflik dengan melibatkan pihak ketiga (mediasi) diluar mekanisme paugeran hukum adat keraton. Terakhir, Mediasi dari Walikota Surakarta berdasar payung hukum Surat Mendagri Nomor 181.1/6619/S] disebutkan bahwa walikota berkoordinasi dengan forum Musyawarah Kepala Daerah (Muspida) dan keluarga Keraton Kasunanan Solo, untuk menyelesaikan konflik serta melindungi keraton sebagai cagar budaya.

Kata kunci: Keraton, Konflik, dan Kearifan Lokal.
\end{abstract}

\begin{abstract}
The purpose of this study was to describe the root causes of conflict and the palace of King Twins conflict resolution patterns Keraton Surakarta Sultanate. The method used is descriptive method sosiolegal . This study is located in the Keraton Surakarta using primary data and secondary data. Techniques of qualitative data analysis by using the theoretical interpretation. The results showed that the root of the problem is basically this conflict began Keraton Surakarta since the death of Paku Buwana XII on June 11, 2004. The conflict between the heir to the throne of Kanjeng Gusti Pangeran Harya (KGPH) Hangabehi and KGPH Tedjowulan born of different mothers. Patterns of conflict resolution involving a third party (mediation) mechanisms beyond traditional law paugeran palace. Lastly, Mediation of legal protection based Surakarta Mayor Letter No. 181.1/6619/S] Minister mentioned that the mayor coordinate with Deliberation forums Regional Head (Muspida) and family Keraton Solo Kasunanan, to resolve conflicts and protect the palace as a cultural heritage.

Keywords : Mediation, Conflict, and Local Wisdom.
\end{abstract}




\section{PENDAHULUAN}

Kota Solo (Surakarta) terletak di Provinsi Jawa Tengah yang dikenal masih melestarikan budaya Jawa yang luhur. Budaya Jawa memuat adat istiadat, sistem tata nilai, norma, pandangan maupun aturan kehidupan yang masih eksis di masyarakat Surakarta. Oleh karena itu, meskipun tergolong kota yang kecil wilayahnya, Surakarta sangat terkenal hingga ke mancanegara. Bahkan, sering disebut kota budaya dengan slogan "Solo The Spirit of Java".

Dalam realitanya, slogan kota budaya semakin memudar. Keraton Surakarta sebagai pilar utama penyangga budaya Jawa masih dirundung permasalahan konflik internal keraton yang sampai sekarang belum berakhir. Ketiadaan acuan yang baku dalam suksesi kepemimpinan Kasunanan menjadi penyebabnya. Dari segi historis perpecahan kekuasaan kerajaan lazim terjadi. Salah satu contohnya Perjanjian Giyanti 1755 telah membagi kerajaan Mataram menjadi dua yakni Kasultanan Yogyakarta dan Kasunanan Surakarta (Imam Samroni, et.al., 2010: 267). Sebuah tragedi menarik untuk diungkap karena selain sarat emosi, juga mempertontonkan karakter putra-putri PB XII, yang melenceng dari ajaran leluhurnya berperilaku bijak dan mengutamakan kepentingan keraton.

Tokoh Nasional pun telah berusaha memfasilitasi penyelesaian konflik Keraton Surakarta. Rekonsiliasi dari ide Jimly Assiddiqie (Mantan Ketua Mahkamah Konstitusi) dan Mantan Gubernur DKI Jakarta, Letjen 
(Purn) Sutiyoso, yang bergelar kebangsawanan Keraton Surakarta Hadiningrat Kanjeng Pangeran Ario (KPA) Yoso Nagoro, merasa terpanggil menjadi penengah atau mediator untuk menyelesaikan konflik yang tidak hanya merugikan keraton tetapi rakyat juga karena masih banyak yang menjadikan keraton dengan segala falsafahnya dijadikan panutan (Kompas, 28/6/2008).

Pemerintah Kota Surakarta tidak tinggal diam, telah berusaha memfasilitasi perdamaian kubu PB XIII Hangabehi dan PB XIII Tedjowulan dengan dilandasi kelestarian jati diri budaya kota Solo (Solopos, 6/11/2010). Dari segi finansial, konflik Raja Kembar jelas sangat merugikan, sebab dana untuk Keraton Surakarta menjadi hilang. Menurut Walikota Surakarta, Joko Widodo (Jokowi), sebenarnya dua tahun terakhir sudah dapat Rp 10 miliar dari Pusat. Tetapi batal dikucurkan, karena Pusat masih melihat keraton belum satu suara (rujuk) (Harian Joglosemar, 23/11/2011).

Ironisnya, konflik Raja Kembar Keraton Surakarta semakin meruncing, dan bertambah parah dengan telah merambah ke ranah hukum. Ketua Lembaga Dewan Adat (LDA) sekaligus Pengageng Sasono Wilopo, GRAy Koes Murtiyah dari PB XIII Hangabehi, merasa telah diobok-obok sehingga memperkarakan masalah ke pengadilan. Alasannya, kelompok tersebut (PB XIII Tedjowulan) dinilai telah melanggar hukum adat Dinasti Mataram, sehingga menciderai budaya leluhur. 
Sejarah baru telah terukir, pada awal Mei 2012, Tedjowulan rela melepas gelar rajanya. Dia pun mengaku mendukung kakaknya memimpin kerajaan dan dia menjadi wakil raja. Pada 16 Mei 2012, perjanjian damai pun ditandatangani kedua raja di sebuah hotel Jakarta dengan disaksikan Wali Kota Solo Joko Widodo dan sesepuh Keraton Surakarta BRA Mooryati Sudibyo. Tedjowulan pun melepas gelar rajanya dan berganti menjadi Kanjeng Gusti Pangeran Haryo Panembahan Agung Tedjowulan (Suara Merdeka, 17/5/2012).

Namun, sungguh aneh bahwa ternyata damai belum berakhir sampai di situ. Saat ingin masuk keraton, Kamis 24 Mei 2012, dua raja (Dwi Tunggal) dihadang dan dilarang masuk. Sejak semula, pengurus keraton memang tidak mengakui Paku Buwono XIII Tedjowulan. Dewan Adat keraton yang tidak menerima rekonsiliasi ini memutuskan tidak mau menerima pasangan dwi tunggal itu (Kompas, 25 Mei 2012). Artinya, rekonsiliasi Raja Kembar PB XIII belum dapat menyelesaikan konflik internal Keraton Surakarta.

Lebih parah lagi, konflik memanas lagi karena Lembaga Adat Keraton Kasunanan Surakarta Hadiningrat mengancam akan melengserkan Sinuhun Paku Buwono (PB) XIII dari Raja Keraton Solo. Ancaman itu menanggapi kisruh dugaan jual-beli gelar kehormatan Keraton Solo yang melibatkan warga Malaysia, menurut Wakil Sasana Wilapa, KP Winarno Kusuma, secara adat, “PB XIII dipercaya menjadi Ketua Adat, tapi segala 
ketentuan ada di tangan lembaga Adat Keraton Solo merupakan lembaga tertinggi yang mempunyai kekuasaan penuh atas segala kebijakan apa pun" (Solopos, 17/12/2012).

Ancaman balik juga dilontarkan Kerabat Dalem Keraton, GPH Suryo Wicaksono bahwa "kalau Lembaga Adat berencana melengserkan Raja, maka bisa dilaporkan pada aparat penegak hukum (polisi)," Pembentukan Lembaga Adat Keraton tanpa didasari persetujuan dari PB XIII Hangabehi dapat dikenakan sanksi hukum. Oleh karena itu, semestinya sebelum adanya wacana pelengseran, Hangabehi bisa mengambil langkah tegas untuk segera mengusir mereka dari keraton (Solopos, 18/12/2012).

Implikasi konflik internal Keraton sekarang ini berdampak negatif belum dapat dicairkannya dana Hibah Keraton sebesar Rp300 juta tahun ini bahkan berpeluang besar hangus. Pemkot Solo menyebut Keraton belum mengirim proposal pencairan beserta lampiran LPJ hingga tenggat akhir yang diberikan (Solopos, 21/12/2012). Selain itu, dana bantuan untuk abdi dalem dari Pemprov Jateng dalam pertahun mencapai $R p$ 1,1 miliar yang diberikan kepada 518 abdi dalem Keraton yang juga tersebar di luar kota juga tersendat.

Sungguh ironis, keraton sebagai simbol budaya Jawa, malah menggunakan pendekatan hukum (formal), yang semestinya lebih mengutamakan nilai-nilai kearifan lokal (local wisdom) budaya Jawa sebagai solusi konflik. Warga Solo pun menggelar aksi dengan membentangkan 
poster Rukun Agawe Santoso Crah Agawe Bubrah di car free day (CFD) JI Slamet Riyadi Solo, Minggu (23/12/2012). Aksi tersebut sebagai bentuk aspirasi warga Kota Solo agar konflik keraton segera selesai (Solopos, 24/12/2012).

Berdasarkan paparan tersebut, penulis tertarik untuk melakukan penelitian dengan perumusan masalah mencari akar masalah konflik keraton Surakarta dan pola penyelesaian yang dilakukan selama ini dikaitkan dengan penerapan local wisdom dalam rangka melestarikan budaya Jawa.

\section{METODE PENELITIAN}

Dalam penelitian ini digunakan metode sosiolegal. Studi sosiolegal merupakan kajian terhadap hukum dengan menggunakan pendekatan ilmu hukum maupun ilmu sosial (Sulistyowati Irianto dan Shidarta, 2009: 174). Penelitian ini menggunakan pendekatan penelitian kualitatif. Penelitian ini berlokasi di Keraton Surakarta Hadiningrat dengan menggunakan data primer maupun data sekunder. Data primer diperoleh dari Narasumber Pengageng Parentah Keraton Surakarta Hadiningrat. Data sekunder diperoleh dari hasil penelaahan literatur yang berkaitan dengan materi penelitian (Mukti Fajar ND dan Yulianto Achmad, 2010: 156). Data sekunder terdiri bahan hukum primer bahan hukum sekunder berupa buku, makalah, data internet, dan bahan hukum tersier. Instrumen pengumpulan 
data dengan cara wawancara mendalam (indepth interviewing) dan studi

dokumen (William L Neuman, 2006: 71). Teknik analisis data secara kualitatif dengan menggunakan theoritical interpretative, yaitu analisis dengan jalan memberikan penafsiran terhadap data yang dikumpulkan dengan mendasarkan pada landasan teori sebagai kerangka berpikir atau sebaliknya.

\section{HASIL PENELITIAN DAN ANALISIS}

A. Akar Masalah Konflik Keraton Surakarta Hadiningrat

Dalam sejarahnya Keraton Surakarta Hadiningrat dipimpin pertama kali oleh Kangjeng Susuhunan Paku Buwono II. Beliau merupakan Raja Terakhir Keraton Kartasura dan sekaligus Raja Pertama Keraton Surakarta memerintah selama 4 (empat) tahun. Dari garis keturunan Paku Buwono II melahirkan Paku Buwono III dan seterusnya hingga sekarang memerintah PB XIII. Jika ditarik jauh kebelakang, bahwa Keraton Surakarta merupakan kelanjutan Keraton Kartasura yang juga merupakan kelanjutan Keraton (Dinasti) Mataram. Sebagaimana diketahui Mataram berdiri pada akhir abad ke-16 Masehi oleh Panembahan Senopati Ing Ngalogo yang merupakan murid Sunan Kalijaga di Kadilangu. 
Adapun tahun berdirinya Keraton Surakarta Hadiningrat diambil dari kepindahan Keraton Kartasura ke Desa Sala, pada hari Rabu tanggal 17 Suro tahun je 1670, sinengkalan “Kombuling Pudya

Kapyarsihing Nata" (tahun Jawa 1670) atau 17 Februari 1945. Menurut ramalan Raden Tumenggung Honggowongso, selaku ahli kebatinan (spiritual) Paku Buwono II bahwa Desa Sala akan membawa keberkahan dan keselamatan sehingga pantas untuk dibangun sebuah Keraton Surakarta sampai berusia 200 tahun. Ada "weca" (ucapan yang menjadi kenyataan) yang menyebutkan bahwa, apabila sebuah keraton didirikan di desa Sala, maka "sandyan kari sak megaring payung tetep lestari". Maksudnya, jika Keraton Surakarta berdiri di desa Sala, keraton tetap ada, eksis meskipun daerah kekuasaanya tinggal selebar terbukanya payung (R.Ay.Sri Winarti P, 2013: 16).

Pada awal pilihan tempat berdirinya Keraton Surakarta Hadiningrat terdapat 3 (tiga) pilihan tempat yakni Kadipolo, Sonosewu, dan Desa Sala. Melalui proses penelitian "nitik karaton" terpilihlah Desa Sala yang dihuni sesepuh desa bernama Kyai Gede Sala atai Kyai Sala seorang abdi dalem Keraton. Desa Sala waktu itu merupakan sebuah rawa ditumbuhi subur pohon-pohon besar dan ditemukan tempat yang daerahnya "wangi". Akhirnya daerah tersebut 
dibeli oleh Paku Buwono II atas saran dari para ahli nujum karena merupakan tanah terbaik.

Akhirnya, ramalan tersebut terbukti setelah duaratus tahun lahirlah Negara Kesatuan Republik Indonesia (NKRI). Paku Buwono XII beserta Ir. Soekarno, dan Mangkubowono VIII menjadi delegasi dalam perundingan di Den Haag, Belanda. Pada saat itu Sinuhun Paku Buwono XII mengeluarkan maklumat bahwa Negara Surakarta berdiri di belakang Republik Indonesia. Maklumat berisi bahwa Negara Surakarta adalah bagian dari NKRI, dan dunia hanya akan mengakui NKRI jika ada pengakuan dari negara yang ada dalam NKRI, pada saat itu yaitu negara Surakarta. Sejak saat itu, Surakarta bukan lagi sebagai suatu negara yang ada dalam NKRI, namun sudah berubah hanya sebagai pemangku adat khususnya adat budaya Jawa.

Dalam menyelenggarakan setiap kegiatan keraton tidak perlu meminta ijin kepada pemerintah kota, sebagai pusat pemerintahan kota Surakarta karena keraton lebih dulu ada sebelum ada Balaikota. Bahkan, sebelum negara Indonesia ada keraton surakarta sudah ada lebih dulu sebagai negara. Sehingga keraton hanya perlu melapor kepada pihak keamanan dalam hal ingin mengadakan suatu kegiatan yang menjadi agenda keraton setiap tahunnya.

Setiap penyelenggaraan event kegiatan budaya keraton yang sudah rutin setiap tahunnya tidak dapat diganggu gugat atau bahkan 
dilarang oleh pemerintah(Aris Suprapto, 2005: 187). Jika pemerintah mempunyai agenda kegiatan yang bersamaan waktunya dengan kegiatan keraton maka kegiatan keraton tetap berjalan dengan dasar bahwa semua kegiatan keraton sudah pasti tanggal pelaksanaannya rutin setiap tahun. Misalnya kegiatan peringatan Malam Satu Sura atau malam peringatan tahun baru dalam kalender Jawa atau yang bertepatan dengan malam satu Muharram dalam penanggalan kalender Islam. Hampir semua kegiatan yang diadakan oleh keraton Surakarta bernafaskan nilai-nilai Islam karena sejarah berdirinya keraton Surakarta adalah dibangun oleh para Wali Songo mulai dari kerajaan Demak sampai di Surakarta.

Dalam menjalankan pemerintahan sumber dana keraton Surakarta berasal dari "Pisungsung" yaitu kepedulian para sentono atau kerabat keraton yang diberikan secara sukarela. Selain itu, pemerintah keraton Surakarta juga menyediakan paket wisata keraton Surakarta bagi para wisatawan dimana keuntungan yang didapat dari paket wisata ini digunakan untuk keberlangsungan kehidupan keraton. Keraton tidak mendapatkan bantuan dana baik dari pemerintah kota Surakarta maupun pemerintah pusat sejak meletusnya konflik.

Konsekuensi tidak menerima bantuan dana pemerintah berimbas pada para abdi dalem yang menjabat sebagai pegawai pemerintahan keraton sehingga dalam beberapa tahun terakhir ini tidak 
menerima gaji. Penghentian bantuan dana dari pemerintah karena disangkut pautkan dengan situasi yang terjadi di dalam tubuh keraton itu sendiri. Yakni mengenai kisruh perebutan tahta kerajaan mengenai siapa yang berhak untuk menjadi sebagi raja antara Hangabehi dengan Tedjowulan. Padahal keraton adalah sebuah institusi bukan hanya pribadi seseorang atau sebagian orang saja, sehingga tidak semestinya pemerintah menjadikan kisruh yang terjadi sebagai alasan untuk menghentikan bantuan dana kepada keraton.

Hubungan keraton Kasunanan Surakarta dengan keraton Kasultanan Yogyakarta merupakan hubungan saudara kandung kakak beradik dimana Sultan Hamengku Buwono I adalah adik dari Sinuhun Paku Buwono II. Dalam perjanjian Giyanti keraton Yogyakarta dilarang untuk membangun bangunan yang sama dengan keraton Surakarta, tidak diperbolehkan mendirikan menara, dan tidak boleh "Marengkang" atau melakukan pemberontakan kepada keraton Surakarta.

Silsilah keraton Surakarta berasal dari Majapahit, kemudian Demak, Pajang, Mataram, Kartasura, dan terakhir di Surakarta yang riwayatnya terus menyambung dari setiap generasi atau dinasti. Keraton surakarta juga melakukan ritual untuk mengunjungi leluhur setiap tahunnya, seperti berkunjung ke makam Sunan Kalijaga di Demak karena berdirinya keraton Surakarta juga di topang oleh para 
Wali Songo. Kemudian ke Panembahan Senopati di Kota Gedhe dan Sultan Agung di Imogiri sampai Paku Buwono XII dimakamkan di Imogiri.

Akar masalah konflik keraton Surakarta ini berawal sejak meninggalnya Paku Buwana XII pada 11 Juni 2004. Keributan tersebut dipicu oleh persengketaan antara Kanjeng Gusti Pangeran Harya (KGPH) Hangabehi dan KGPH Tedjowulan yang lahir dari ibu yang berbeda. Penyebab konflik karena perbedaan keyakinan (Bambang Sugeng, 2011: 1). Persengketaan tersebut tentang pewaris tahta kerajaan. Dalam tradisi kerajaan Jawa, pengganti raja yang adalah anak lelaki tertua dari permaisuri, sementara sampai Paku Buwana XII meninggal tidak mengangkat seorang permaisuri. Pasca konflik, keadaan Keraton Surakarta semakin memburuk.

B. Pola penyelesaian konflik Keraton Surakarta Hadiningrat

1. Penerapan Local Wisdom Budaya Jawa

Dalam keraton Kasunanan Surakarta Hadinigrat sebagai pemangku adat adalah bertumpu pada sosok seorang raja, karena raja merupakan figur yang sangat sentral dalam tubuh pemerintahan keraton. Namun dengan kondisi sekarang, dimana raja keraton Surakarta Paku Buwono XIII sinuhun Hangabehi dinilai sudah melanggar dari hukum adat yang berlaku di keraton, maka 
tugas untuk menjaga agar nilai-nilai hukum adat berupa paugeran yang ada di keraton tetap dijalankan diambil alih oleh Lembaga Dewan Adat.

Sejarah munculnya Lembaga Dewan Adat sebenarnya sudah ada sejak dahulu dengan nama berbeda yaitu Paran Parakarsa dan Paran Paranata barulah setelah masa pemerintahan PB XIII yang dianggap telah melakukan pelanggaran terhadap hukum adat, akhirnya kedua lembaga itu melebur menjadi Dewan Adat yang anggotanya masih orang-orang yang sama yang merupakan Trah atau keturunan mulai dari PB II sampai dengan PB XII yang pendiriannya disahkan dengan akta notaris. Tugas pokok dari Lembaga Dewan Adat adalah untuk menjaga dan mempertahankan nilai-nilai budaya keraton Surakarta.

Upaya telah dilakukan oleh Lembaga Dewan Adat untuk menyelesaiakan konflik yang terjadi dalam tubuh keraton itu sendiri. Salah satu caranya melalui akomodasi dari pihak yang berkonflik (J. Dwi Narwoko dan Bagong Suyanto: 2007: 70). Namun, upaya itu akan terasa susah dijalankan dengan kondisi sinuhun PB XIII yang sakit dengan keadaan psikomotorik yang melemah, dan dokter telah memvonis bahwa sakit yang diderita oleh sinuhun tidak bisa sembuh. Hal inilah yang dimanfaatkan oleh pihak-pihak yang mempunyai kepentingan lain terutama istri 
sinuhun. Lembaga Adat juga sudah memberikan teguran berupa surat tertulis yang ditujukan kepada sinuhun PB XIII, namun belum juga ada perbaikan dari sikap sinuhun justru Lembaga Dewan Adat dianggap sebagai musuh oleh sinuhun.

Sejak sinuhun dianggap telah menyimpang dari hukum adat keraton maka semua kegiatan keraton diambil alih oleh Lembaga Dewan Adat. Lembaga ini yang melaksanakan semua upacara-upacara adat keraton sehingga tanpa sinuhun pun upacara adat keraton tetap berjalan sebagaimana mestinya karena raja bukan lagi sebagai penguasa tunggal.

Mengenai konflik yang terjadi di dalam keraton Kasunanan Surakarta Hadiningrat yang mulanya berawal dari perebutan tahta kerajaan dengan munculnya konflik raja kembar, sampai akhirnya konflik raja kembar ini berakhir dengan salah satu pihak yaitu KGPH Tedjowulan mengalah untuk tidak menjadi raja, tetapi hanya menjadi maha patih untuk PB XIII sinuhun Hangabehi. Kemudian berlanjut dengan munculnya konflik antara raja dengan mahapatihnya dan Lembaga Dewan Adat.

Pola penyelesaian konflik yang dilakukan selama ini yaitu dengan menggunakan paugeran atau nilai-nilai hukum adat keraton yang sudah berlaku turun temurun dari mulai PB II sampai dengan PB XIII. Ada keterkaitan antara nilai-nilai yang merupakan hasil 
budaya dan hukum adat (I Gede S.B.Wiranata, 2005: 88). Sungguh besarnya fungsi hukum dan konflik bagi kehidupan manusia, posisi hukum berfungsi dan berperan untuk pengelolaan konflik (Sabian Utsman, 2010: 379). Hukum sebagai media penyelesaian konflik tidak boleh hanya dipahami secara parsial melainkan secara komprehensif. Hukum dalam bentuknya tidak selamanya tertulis (hukum nasional) tetapi juga berbentuk tidak tertulis (unastatutory law) yang sering dikenal dengan istilah hukum adat.

Hukum adat keraton merupakan sumber hukum tertinggi yang dijadikan sebagai patokan untuk menyelesaikan setiap masalah yang terjadi di dalam keraton, khususnya yang menyangkut permasalahan antara kerabat abdi dalem keraton. Dalam hal menentukan siapa yang berhak untuk melanjutkan tahta kerajaan adalah sesuai dengan "Paugeran" atau Pranatan yang tidak tertulis namun diakui diterima dilaksanakan dan dihormati secara turuntemurun sebagai hukum adat yang berlaku di dalam keraton. Misalnya dalam keraton terdapat sebuah Paugeran yang mengharuskan setiap abdi dalem untuk menyembah yang berarti untuk sebuah penghormatan. Hal ini seperti ini tidak diatur secara tertulis, namun tetap dilaksanakan dan dihormati oleh semua abdi dalem. 
Dengan kondisi sekarang dimana raja keraton surakarta $P B$ XIII sinuhun Hangabehi yang sudah tidak diakui lagi sebagai raja oleh Lembaga Dewan Adat dengan dicabutnya kewenangan raja dalam hal menentukan kebijakan keraton dan semua tugas mengenai berjalannya pemerintahan keraton Surakarta dikembalikan kepada Lembaga Dewan Adat, maka hukum yang berlaku untuk setiap perselisihan yang terjadi di dalam keraton Surakarta adalah hukum adat keraton yang mencerminkan nilainilai local wisdom dan mengandung tujuan untuk pelestarian nilainilai budaya Jawa. Hukum adat merupakan bagian dari adat istiadat, memiliki asas-asas yang berasal dari budaya masyarakat, sebagai norma tidak tertulis yang dibuat dan/atau dipertahankan serta mengandung sanksi (Idrus A. Paturusi, 2009).

2. Pola PelibatanPihak Ketiga (Mediasi)

Pemerintah Provinsi (Pemprov) Jawa Tengah hanya menyarankan supaya konflik diselesaikan melalui cara musyawarah dengan kepala dingin. Sebagai pusat kultural, ujarnya keraton memiliki paugeran (peraturan tidak tertulis) yang bisa menjadi dasar dan pola penyelesaian sendiri. Hukum adat merupakan hukum tidak tertulis yang dipertahankan oleh fungsionaris hukum dan mengandung sanksi (Otje Salman Soemadiningrat, 2002: 
218). Dalam urusan yang berkaitan dengan konflik internal keraton, negara memilih tidak terlibat. Kalau pun terlibat, hanya terbatas pada upaya memfasilitasi. Wali Kota mengatakan, tujuan utama mediasi yakni mendudukkan kembali PB XIII Hangabehi di Sasana Sewaka. Sejak perselisihan pasca rekonsiliasi tahun 2012, PB XIII tidak lagi berada di singgasananya.

Akhirnya pada hari Jumat (4 Oktober 2013), dua kubu yang berseteru di Keraton Kasunanan Surakarta, PB XIII Hangabehi dan Ketua Dewan Adat Keraton GKR Wandansari atau lebih dikenal GKR Koes Moertiyah atau Gusti Moeng, menghadiri proses mediasi yang digelar Pemkot di Bale Tawangarum, Balai Kota Solo. Mediasi yang berlangsung 150 menit itu dihadiri 24 putra-putri dalem PB XII. Selain Mbak Moeng, tampak putra dalem dari kubu dewan adat seperti GRAY Kus Indriyah, GKR Isbandiyah dan KGPH Puger. Sedangkan dari kubu pro rekonsiliasi hadir KGPAA Tedjowulan, KGPH Benowo, GPH Madukusumo, Gusti Kanjeng Ratu Alit hingga KGPH Dipokusumo.

Sekitar pukul 13.30 WIB, dua kubu itu sudah duduk di ruang mediasi yang dipimpin Wali Kota Solo F.X. Hadi Rudyatmo dan sejumlah Muspida, seperti Ketua DPRD Y.F. Sukasno, Dandim 0735 Solo Sumirating Baskoro, Kapolres AKBP Iriansyah dan budayawan Sardono W Kusumo. Dengan mengenakan batik warna 
coklat, Sinuhun Hangabehi didampingi Mahapatih KGPAA Tedjowulan. Sementara, GKR Wandansari yang mengenakan batik merah didampingi beberapa putra dalem seperti GPH Puger dan GKR Koes Indriyah.

Penyelesaian konflik Keraton Solo yang melibatkan kubu dewan adat dan kubu pro rekonsiliasi diyakini masih butuh waktu panjang. Mediasi merupakan cara penyelesaian konflik dengan melibatkan pihak ketiga (Pheni Chalid, 2005:107-108). Mediasi yang digelar tertutup di Bale Tawangarum, Balai Kota, Jumat (4/10/2013), belum membuahkan hasil yang signifikan. Artinya, belum mampu menjawab tuntas polemik yang ada di tubuh Keraton.

Ketua Lembaga Dewan Adat Keraton, GKR Wandansari (Mbak Moeng), kukuh meminta Mahapatih, KGPAA Tedjowulan, tak menginjak Keraton Solo jika Raja Keraton Solo, Paku Buwono (PB) XIII ingin kembali ke singgasananya di Sasana Sewaka. Jika ingin turut diterima di Keraton, Mbak Moeng menuntut pertanggungjawaban adat dari Tedjowulan atas upaya makar beberapa tahun lalu.

Selanjutnya, Kubu Lembaga Adat Keraton Solo menyatakan tak ada surat dari Menteri Dalam Negeri (Mendagri) kepada Wali Kota Solo, F.X. Hadi Rudyatmo (Rudy), untuk 
mengadakan mediasi jumenengan Paku Buwono (PB) XIII yang sudah dilakukan di balai kota, 4 Oktober lalu. Diduga, surat mediasi dari Mendagri tersebut palsu (Solopos, 17 Oktober 2013). Pengageng Sasana Wilapa, G.K.R. Wandansari (Mbak Moeng) beserta suami K.P. Eddy Wirabhumi serta seorang kerabat keraton lainnya melakukan konfirmasi ke Kementerian Dalam Negeri (Kemendagri). Dalam kesempatan itu, mereka menemui Dirjen Kesbangpol Kemendagri, A. Tanribali Lamo, didampingi Kasubdit Ketahanan Budaya, Djuariah. Berdasarkan hasil konfirmasi, Dirjen Kesbangpol menyatakan tidak ada surat Mendagri ke Walikota untuk melakukan mediasi.

Menurut KP Edy Wirabumi, kunjungan pertama ke kemendagri, pihak Dewan Adat belum bisa mendapatkan jawaban langsung dari pihak Dirjen Kesbangpol. Pasalnya menyangkut surat keluar harus ditanyakan kembali kepada dirjen lainnya yang ada di Kemendagri. Pada keesokan harinya, baru mendapatkan jawaban dari Kasubdit Ketahanan Budaya, Djuariah yang menyatakan tidak ada surat Mendagri yang ditujukan pada Walikota Solo untuk melakukan mediasi bagi kedua belah pihak di Keraton Kasunanan Surakarta.

Menjawab perlawanan Kubu Dewan Adat yang menduga surat dari Mendagri itu palsu, Walikota Surakarta FX Rudy 
memastikan surat tersebut asli. Sebagai bukti dia menunjukkan surat asli yang ditandatangani Gamawan Fauzi dibubuhi stempel serta tembusan ke sejumlah pejabat negara, termasuk Presiden Republik Indonesia. Wali Kota Solo FX Hadi Rudyatmo mempertanyakan sikap penolakan kirab kembalinya Raja Solo PB XIII yang dilakukan para sentono dalem Keraton Surakarta. Walikota menilai penolakan para sentono itu tidak ada dasarnya sama sekali. Sedangkan kirab itu sendiri bagian dari hasil upaya damai yang dilakukan pihak Pemerintah Kota (Pemkot) Solo sesuai dengan perintah Menteri Dalam Negeri nomer 181.1/6619/S] tertanggal 2 Oktober 2013. Surat itu berisi perintah pada saya untuk bertindak sebagai mediator menyelesaikan masalah internal Keraton dengan berkoordinasi dengan forum Musyawarah Kepala Daerah (Muspida) dan keluarga Keraton Kasunanan Solo, menyelesaikan konflik serta melindungi keraton sebagai cagar budaya. Tak ada yang salah dalam pertemuan mediasi tersebut. Dirinya sama sekali tak berniat melakukan intimidasi saat mediasi berlangsung sebagaimana materi laporan ke Komnas HAM.

Rudy meminta para keturunan PB XII tidak beranggapan konflik tersebut sebatas konflik internal saja. Pihak di luar keraton, termasuk Wali Kota tidak boleh ikut campur dalam konflik tersebut adalah salah besar. Pasalnya, konflik internal saat ini sudah meluas 
ke luar tembok keraton. Konflik itu sudah berubah menjadi konflik sosial yang imbasnya mengancam keberadaan keraton sebagai salah satu benda cagar budaya yang harus dilindungi. Meski ada penolakan dari para sentono, Rudy akan tetap menggelar kirab kembalinya Raja Solo ke dalam Keraton Kasunanan Surakarta. Menyangkut mediasi lanjutan, Rudy mengaku belum bisa memastikan. Pihaknya mencoba kembali menemui para kerabat keraton yang bertikai untuk kembali duduk bersama menyelesaikan secara menyeluruh kemelut yang terjadi di Keraton Kasunanan Surakarta.

\section{SIMPULAN DAN SARAN}

A. Simpulan

1. Akar masalah konflik raja kembar Kasunanan Surakarta ini berawal sejak meninggalnya Paku Buwana XII pada 11 Juni 2004. Keributan tersebut dipicu oleh persengketaan antara Kanjeng Gusti Pangeran Harya (KGPH) Hangabehi dan KGPH Tedjowulan yang lahir dari ibu yang berbeda. Persengketaan tersebut tentang pewaris tahta kerajaan. Dalam tradisi kerajaan Jawa, pengganti raja yang adalah anak lelaki tertua dari permaisuri. Akhirnya, konflik keraton semakin memanas antara raja PB XIII sinuhun Hangabehi dengan Lembaga Dewan Adat. 
2. Pola penyelesaian konflik yang terjadi di tubuh keraton Kasunanan Surakarta Hadinigrat yang melibatkan pihak ketiga (mediasi) diluar mekanisme paugeran hukum adat keraton. Terakhir, Mediasi dari Walikota Surakarta berdasar payung hukum Surat Mendagri Nomor 181.1/6619/S] disebutkan agar walikota berkoordinasi dengan forum Musyawarah Kepala Daerah (Muspida) dan keluarga Keraton Kasunanan Solo, menyelesaikan konflik serta melindungi keraton sebagai cagar budaya.

B. Saran

1. Dalam hal menyelesaikan setiap konflik yang terjadi di dalam keraton Surakarta baik konflik mengenai raja kembar antara PB XIII Sinuhun Hangabehi dengan Maha Patih Tedjowulan, maupun konflik yang terjadi antara raja keraton Surakarta Paku Buwono XIII sinuhun Hangabehi dan Lembaga Dewan Adat, hendaknya tetap menggunakan paugeran atau nilai-nilai hukum adat yang berlaku di dalam keraton itu sendiri, sehingga lebih mengutamakan local wisdom bukan jalur litigasi (pengadilan).

2. Hendaknya setiap pihak yang berkonflik lebih mengutamakan kepentingan keraton sebagai institusi budaya daripada institusi politik yang berujung pada perebutan kekuasaan semata. Nilai-nilai hukum adat keraton yang mengandung local wisdom yang 
mencerminkan budaya Jawa yang terus dilestarikan dan dilaksanakan turun temurun.

\section{DAFTAR PUSTAKA}

Bambang Sugeng, 2011, Penanganan Konflik Sosial, Bandung, Pusat Kajian Bencana dan Pengungsi (PUSKASI) STKS.

I Gede S.B.Wiranata, 2005, Hukum Adat Indonesia: Perkembangannya dari Masa ke Masa,Bandung, PT Citra Aditya Bakti.

Idrus A. Paturusi, 2009, Esensi dan Urgensitas Peraturan Daerah dalam Pelaksanaan Otonomi Daerah, Laporan Hasil Penelitian Kerjasama Dewan Perwakilan Daerah Republik Indonesia (DPD-RI) dan Universitas Hasanuddin.

Imam Samroni,et.al., 2010, Daerah Istimewa Surakarta: Wacana Pembentukan Provinsi Daerah Istimewa Surakarta ditinjau dari perspektif Historis, Sosiologis dan Filosofis Yuridis, Yogyakarta, Pura Pustaka.

J. Dwi Narwoko dan Bagong Suyanto, 2007, Sosiologi: Teks Pengantar dan Terapan, Jakarta, Kencana Prenada Media Group.

Mukti Fajar Nur Dewata dan Yulianto Achmad, 2010, Dualisme Penelitian Hukum Normatif dan Empiris, Yogyakarta, Pustaka Pelajar. 
Otje Salman Soemadiningrat, 2002, Rekonseptualisasi Hukum Adat Kontemporer, Bandung, Alumni.

Pheni Chalid, 2005, Otonomi Daerah: Masalah, Pemberdayaan, dan Konflik, Jakarta, Kemitraan.

Sabian Utsman, 2010, Dasar-dasar Sosiologi Hukum: Dilengkapi Proposal Penelitian Hukum (Legal Research), Yogyakarta, Pustaka Pelajar.

Sri Winarti P, 2013, Sekilas Sejarah Karaton Surakarta, Cetakan Kelima Edisi Revisi, Sukoharjo, CV Cenderawasih.

Sulistyowati Irianto dan Shidarta, 2009, Metode Penelitian Hukum: Konstelasi dan Refleksi, Jakarta, Yayasan Obor Indonesia.

William L Neuman, 2006, Social Research Methods, Qualitative and Quantitative Approaches, Sixth Edition, USA, Pearson.

Tesis

Aris Suprapto, 2005, Analisis Penawaran dan Permintaan Wisata Dalam Pengembangan PotensiPariwisata di Keraton Surakarta Hadiningrat, Semarang: Tesis pada Program Pasca Sarjana Magister Teknik Pembangunan Wilayah dan Kota, Universitas Diponegoro.

\section{MEDIA MASSA}

Harian Joglosemar, 23 November 2011.

Kompas, 28 Juni 2008.

-------, 25 Mei 2012. 
Solopos, 6 November 2010.

-.---.---, 17 Desember 2012.

-.--.-----, 18 Desember 2012

21 Desember 2012.

24 Desember 2012.

17 Oktober 2013.

Suara Merdeka, 17 Mei 2012. 